\title{
Relaciones entre medios
}

\section{Media relations}

Julio Gracia Lana

Universidad de Zaragoza jaglana@unizar.es

Código ORCID: https://orcid.org/0000-0002-2138-0554

La segunda etapa de Neuróptica continúa su andadura con un número en el que seguimos tratando de mejorar la publicación, así como la estructura e impacto de cada texto publicado. Para ello hemos contado con el aporte indispensable de las autoras y autores que han participado en el número y de los comités que aseguran la calidad del contenido. Al igual que en el primer número, el Comité Científico se ha constituido específicamente para la evaluación de los textos que configuran el ejemplar, incorporando a varios profesores e investigadores ajenos a los comités de la revista. Desde aquí nuestro más sincero agradecimiento por desarrollar su trabajo con rigor y detalle.

El número se edita gracias al patrocinio del Vicerrectorado de Política Científica de la Universidad de Zaragoza y se apoya de forma destacada en la Fundación para la creación e investigación en cómic. El arte de volar, creada por Antonio Altarriba. La revista se edita con el sello de calidad que supone Prensas Universitarias de Zaragoza, editorial muy bien clasificada en el Scholarly Publishers Indicators (SPI) y de referencia dentro de las ediciones académicas españolas.

En esta ocasión, el monográfico se dedica a las relaciones entre cómic y cine, entendidas de una manera muy amplia bajo el título «De la página en blanco al espacio fílmico». Este importante apartado que vertebra el número ha podido realizarse gracias a Gonzalo M. Pavés, Profesor Titular en la Universidad de La Laguna, al que agradecemos desde este editorial inicial su trabajo y confianza en la revista. La orientación temática se ha definido tratando de configurar múltiples puntos de vista que otorgaran una visión de conjunto sobre un tema que permite numerosas indagaciones teóricas. En los distintos textos se tratan temas capitales para comprender las relaciones entre la historieta y el audiovisual. Encontramos, por supuesto, el análisis de cómics concretos, cuyos casos particulares tienen como objetivo definir 
conclusiones de carácter global: Marcos Rafael Cañas aborda el estudio de El Viejo Ojo de Halcón, mientras que Alicia Hernández destaca las adaptaciones del clásico de Edgar Allan Poe La caída de la Casa Usher, por Roger Corman y Richard Corben. Dulce Ivette Muñoz se acerca a Watchmen, en un prisma complementario al foco situado por Sandra Medina en Alan Moore. Jacqueline Venet y Rainer Rubira plantean un vibrante análisis en torno a la obra de Carlos Vermut. Se desarrollan también enfoques que logran identificar elementos comunes a un contexto amplio. Se constituyen como estudios transversales los acercamientos de Débora Madrid, centrado en los años noventa en España, o el firmado por Tomás Martín sobre el concepto de cíborg.

Julio Santamaría, doctor con una tesis en el tema, escribe sobre las conexiones fílmicas de Blacksad. El reconocido y exitoso personaje de Juan Díaz Canales y Juanjo Guarnido abre además la portada de este número. Francisco Sáez de Adana aporta al ejemplar un minucioso recorrido por las relaciones entre el cómic y el serial cinematográfico de los años 30 y 40. Investigación clave para entender la historiografía sobre las conexiones entre medios, que forma parte de una colaboración entre Neuróptica y la revista Tebeosfera. Ambas han dedicado sendos monográficos de forma contemporánea a los caminos de ida y vuelta entre dichas manifestaciones artísticas.

En el apartado de varia Claudia Bonillo y María Gutiérrez analizan la obra Pájaro que trina no vuela de la autora nipona Yoneda Kō, mientras que Lydia Vázquez y Juan Manuel Ibeas se aproximan a la producción de Claire Bretécher. Ambos artículos abren el foco a las autoras, dejando atrás un prisma historiográfico que tradicionalmente ha privilegiado el análisis de las firmas masculinas. Juan R. Coca disecciona cuidadosamente los distintos elementos que componen Batman/Deathblow, de Brian Azzarello y Lee Bermejo. Alejandro Silvela desarrolla un prisma novedoso sobre la adaptación de la Salomé de Richard Strauss realizada por Philip Craig Russell. Traza las conexiones entre viñeta y música, llevando todavía más allá las posibilidades de análisis intermedial que ofrece el cómic.

La sección de reseñas ha sido coordinada gracias al apoyo de la investigadora Lisa Maya Quaianni, perteneciente al WOW Spazio Fumetto de Milán. Le agradecemos muy destacadamente el trabajo para resaltar obras importantes en el medio y diversas. El reciente (y adecuado al presente número de Neuróptica) aporte teórico de Daniele Barbieri Letteratura a fumetti? Le impreviste avventure del racconto aparece referenciado por Lorenzo 
Barberis, Marco D'Angelo y Simone Rastelli. El investigador de la Universidad de Gante Giorgio Busi define la relevancia de L'inafferrabile medium. Una cartografia delle teorie del fumetto dagli anni Venti a oggi de Lorenzo Di Paola y David García Reyes se aproxima a Cómics y memoria en América Latina, editada desde Cátedra por parte de Jorge L. Catalá Carrasco, Paulo Drinot y James Scorer. Por último, las reseñas de José Manuel Trabado y Ana Asión insisten en los vínculos entre la historieta y otros medios. El primero reseña Dúplex. Poesía y cómic, editado por Enrique del Rey Cabero y Francisco Sáez De Adana. Se trata de un importante y cuidado esfuerzo colaborativo entre poetas y dibujantes. Por otro lado, el detallado acercamiento a Filmish. Un viaje grafico por el cine cierra perfectamente un número centrado en las relaciones entre la lectura de las viñetas y el visionado audiovisual en las salas de cine.

El ejemplar se ha desarrollado en un 2020 terrible para todos y que ha afectado al funcionamiento de las universidades y centros de investigación. La labor teórica y la reivindicación de las Humanidades tienen que permanecer en estos tiempos inciertos. El caos y la destrucción generados durante la pandemia no deben servir para que ninguna administración de marcha atrás en conquistas ya logradas. Debemos consolidar lo conseguido y seguir avanzando con paso firme. Ahora más que nunca es momento de comprender, proteger y conservar mejor nuestro patrimonio gráfico y audiovisual. Páginas en papel y fotogramas forman parte inseparable y se constituyen como un privilegiado reflejo de nuestra sociedad. 